\title{
Wheel Attachment Failures in Light-Duty Vehicles
}

\author{
James D. Varin
}

Submitted: 24 May 2017/Published online: 5 July 2017

(C) ASM International 2017

\begin{abstract}
The frequency of vehicle accidents attributable to wheel attachment failures on light-duty (non-dual rear wheel) vehicles was extremely low prior to the advent of cast and forged aluminum alloy and forged "styled steel" wheels in the early 1970s. The sharp increase in such accidents which accompanied the rapid increase in the popularity of the more attractive solid wheels was attributable to a widespread failure among many after-market (and some OEM) suppliers and service organizations to recognize that the stiffer cast and forged wheels required more stringent installation and maintenance standards than did the more "forgiving" stamped steel predecessors. Coincident with, but not in response to, the increased frequency of wheel attachment failures on lightduty vehicles, hub-piloted wheels were introduced on heavier (dual rear wheel) vehicles as a means of reducing the longstanding higher frequency of attachment failures on vehicles equipped with the heavy-gage forged steel wheels. This reduction was accomplished by increasing the portion of the installation torque converted to wheel clamp force through a reduction in the portion lost to nut-to-wheel friction. Failure on the part of some investigators to recognize the factors responsible for the increased incidence of wheel separations on light-duty vehicles and the unique features of hub-piloted wheels gave rise to the formulation and propagation of myths and misconceptions regarding the causes and cures for such separations. It is the purpose of this article to identify critical features of wheel and wheel attachment designs and of their installation and maintenance requirements that relate directly to attachment failures and to dispel some of those myths and misconceptions.
\end{abstract}

\footnotetext{
J. D. Varin $(\bowtie)$

Varin Consulting Services, 930 Normandy Rd., Royal Oak, MI 48073, USA

e-mail: jdvarin@cs.com
}

Keywords Wheel attachments - Wheel bolt failures . Fatigue failure of bolts $\cdot$ Wheel separations

\section{Introduction}

Wheel attachments, as the term implies, consist of the wheel nuts and wheel bolts which serve to secure the road wheels of a vehicle to the rotating axles or stationary hubs. Their principal function is to provide a means of transmitting the gravitational, dynamic, driving, braking, and steering forces and torques between the wheels and the driveline, steering, and suspension components. Failure of the attachment components, either through loosening and "backing off" of the wheel nuts or through fracture of the wheel bolts, leads to separation of the wheel from the vehicle and possible loss of vehicle steering and/or braking control. This very often leads to a serious accident. The term "light-duty vehicles" is intended to refer to passenger cars, light trucks, vans, sport utility vehicles, and other four-wheel vehicles having a gross vehicle weight rating of less than approximately 11,000 pounds. It is not intended to include medium or heavy trucks or motorcycles, although many of the observations and conclusions expressed herein may have direct application to such vehicles.

\section{The Basics of Wheel Attachments}

The basic wheel attachment system as it existed on lightduty vehicles in the 1960s is illustrated in Fig. 1. The figure shows a bolt-piloted, stamped steel wheel attached to an axle shaft and brake drum or rotor using serrated wheel bolts and conical wheel nuts. The term "bolt-piloted" refers to the fact that the wheel bolts serve also to "center" 


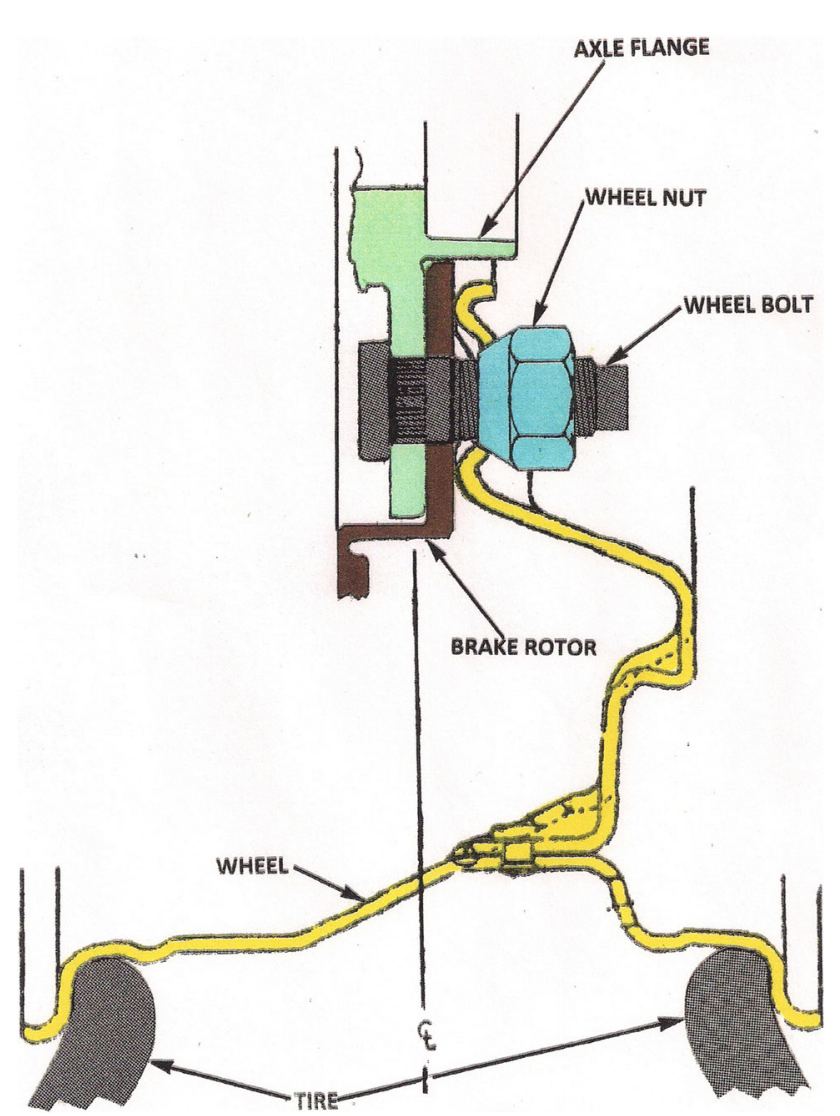

Fig. 1 Conventional stamped steel wheel

the wheel on the brake drum or rotor. The stamped wheel was relatively flexible, particularly in the area of the wheel nut seat where the flexible cone seat acted somewhat as a Belleville spring. Heavier vehicles, such as those equipped with dual rear wheels, were equipped with heavier gage, forged steel wheels offering much less compliance. In the early 1970s, cast aluminum alloy and forged "styled steel" wheels became popular on light vehicles, and wheel separations, which had been very uncommon with the stamped wheels, became a major concern, with frequencies approaching those previously experienced in the heavier vehicles equipped with forged steel wheels. Then, in the early 1980s hub-piloted wheels came into use, primarily on vehicles equipped with forged, dual rear wheels. The term "hub-piloted" refers to the fact that the wheel is "centered" by a close fit between the wheel center hole and the projecting hub. The hub-piloted wheel attachment components differed from bolt-piloted components in small but very significant ways, and the attachments are compared in the sketches of Fig. 2. The significance of the differences in the components of the two systems will be described in greater detail in a subsequent section.

The mechanics of securing the wheel to its mating component (i.e., a brake drum or rotor) is the same for both bolt-piloted and hub-piloted systems: the radial and
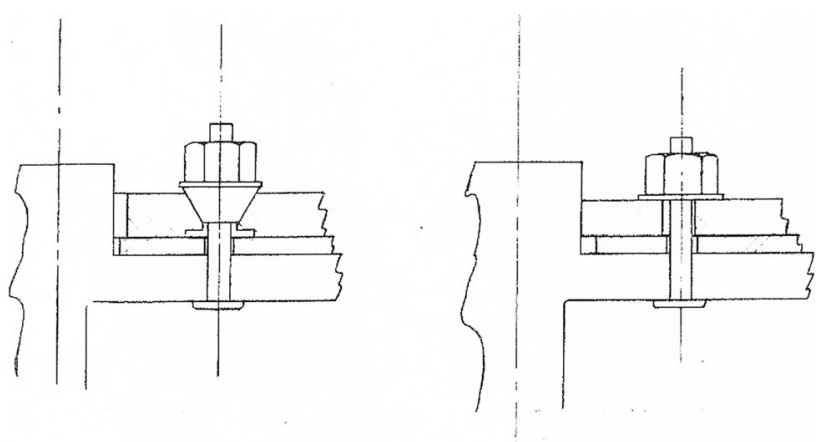

Fig. 2 Bolt-piloted wheel (left) and hub-piloted wheel (right)

torsional road loads are all transferred from the wheel through a combination of the friction connection between the wheel and its mating component, and the shear and bending forces applied by the wheel through the wheel nuts to the wheel bolts. The friction connection is created by the "clamp force" that arises during the tightening of the wheel nuts on the wheel bolts. Tightening the nut "stretches" the bolt and clamps the wheel tightly against its mating component. This clamping action and the resulting friction connection between the wheel and rotor or drum resists any tendency for the wheel to move relative to its mating component under the influence of the applied road loads or acceleration or braking torques. It is intuitively apparent, and it has been confirmed through both the testing of strain-gaged wheel bolts and through finite element analysis that a portion of the radial and torsional forces applied to the wheel must also be transferred through the wheel nuts to the wheel bolts. The division of the loads between the two paths (the friction connection and the wheel bolts) has been described by Parisen [1] and is shown in Fig. 3, reproduced from his paper. Although Parisen's curves were derived specifically for the torsional wheel loads arising during vehicle acceleration and braking, independent vehicle tests utilizing strain-gaged wheel bolts in which vehicle weights and wheel nut torques were varied have confirmed that the basic characteristics of Parisen's curves also apply to the vertical gravity forces acting on the wheel. Additional confirmation has been obtained through finite element analyses. The function of the wheel attachment components (the wheel bolt, wheel nut, and wheel nut seat) then is to provide sufficient clamp force to prevent relative motion of the wheel while limiting the forces applied to the wheel bolts to those which it can successfully resist over the useful life of the vehicle. This is accomplished through the careful selection of wheel design, the number and size of the wheel bolts, the wheel nut configuration, and the nut tightening torque. In a properly designed wheel attachment system, wheel separation should not occur unless the clamp force is overcome through over-loading of the axle or through either 


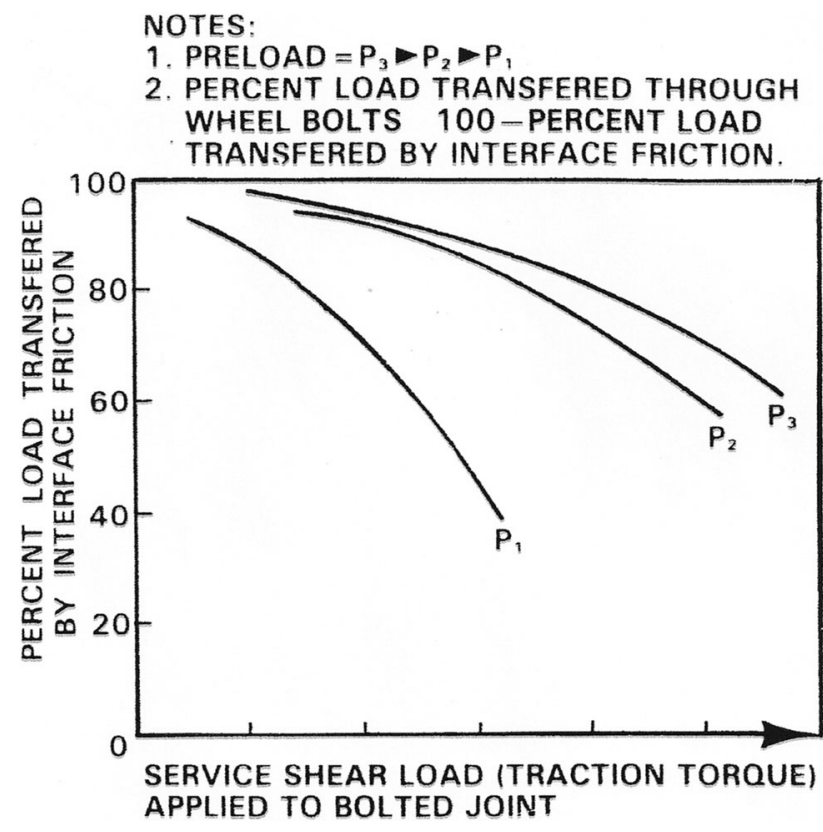

Fig. 3 Distribution of service shear load in a wheel attachment. From Parisen [1]

insufficient nut installation torque, improper nut torque maintenance or loss of clamp force during vehicle operation.

The loss of some portion of the installation clamp force over time and during vehicle operation is inevitable and is attributable to several factors. Because of the imperfect mating of parts, there will always be small areas in the wheel nut seat, the wheel nut, and the wheel bolt in which high local stresses are created. Such imperfections are necessarily present in the nut seat areas of the wheel, especially those in which conical or spherical wheel nuts are used. This is because there will always be some amount of mismatch between the wheel bolt, the nut, and the nut seat. This situation has been described in some detail by Searle [2], who illustrated one aspect of this mismatch in the sketch of Fig. 4, taken from his paper. Although the effects of mismatch can be minimized by modern machining methods, they cannot be eliminated. Over time, these high local stresses are reduced through the process of creep relaxation, and the resulting conversion of high local elastic strains to plastic strains causes a loss of bolt tension (clamp force) and residual nut torque. This effect is compounded during vehicle operation by the higher-thanambient operating temperatures and by the additional forces applied to the wheels, particularly during cornering maneuvers and rough-road operation. These effects are more apparent in aluminum than steel wheels because of the greater resistance of steel to creep relaxation and the greater effect of increased temperature on the strength characteristics of aluminum alloys. To counteract the

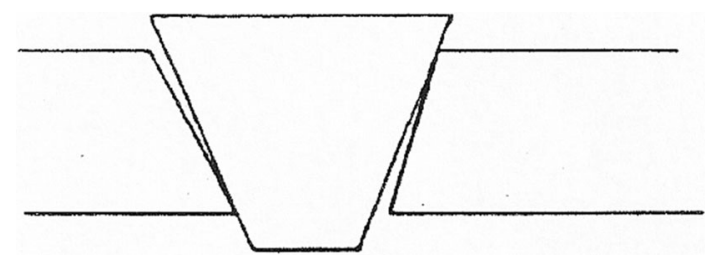

Fig. 4 One type of mismatch contributing to loss of clamp force. From Searle [2]

tendency for loss of clamp force, some automotive manufacturers have required users to re-tighten the wheel nuts after a specified interval (such as 100 or 500 miles) each time a wheel has been removed and re-installed. (At least one manufacturer has required a re-tightening procedure on vehicles equipped with aluminum alloy wheels, but not stamped steel wheels.) It has been assumed by some investigators that creep relaxation does not occur in structural metals at room temperature [3] and therefore that creep-induced loss of clamp force does not occur in wheel attachments. It has been known for many years, however, that creep does occur in both steel and aluminum at room temperature, as shown, for example, in the room temperature creep curves provided in Fig. 5. The lower-strength curves of Fig. 5 were generated in the 1930s by Sturm et al. [4] on pure aluminum; the higher-strength curves were generated by this author on specimens machined from aluminum alloy wheels manufactured as OEM equipment for a major automobile manufacturer. The location of the creep specimens in the wheel is shown in Fig. 6. The specimens were machined by LAM Industries of Livonia, MI, and the creep testing was performed by Materials Technologies of Ann Arbor, MI. Similar creep curves have been generated at room temperature on high-strength steel specimens. The creep curves shown in Fig. 5 show only modest amounts of creep elongation, but the tests were necessarily conducted in tension and the applied stresses were therefore limited to values much lower than the ultimate tensile strength of the material. The high, local mismatch stresses in wheel nut seats are predominately compressive; however, and their values can greatly exceed the tensile strength of the material. The resulting creep strains will therefore greatly exceed the values shown in Fig. 5. The effects of creep relaxation on the steel nuts and bolts have been described by Bickford [5] and are illustrated in his sketch reproduced here as Fig. 7. The effects of creep relaxation in these curves appear to have almost disappeared after the passage of $24 \mathrm{~h}$, but that is true only for the threaded steel components and only at room temperature. Also, the increased forces applied to the bolts as the vehicle is loaded and during vehicle operation give rise to additional creep relaxation. An aluminum alloy wheel will continue to exhibit relaxation after $24 \mathrm{~h}$ due to the lower creep resistance of aluminum. There is no question 


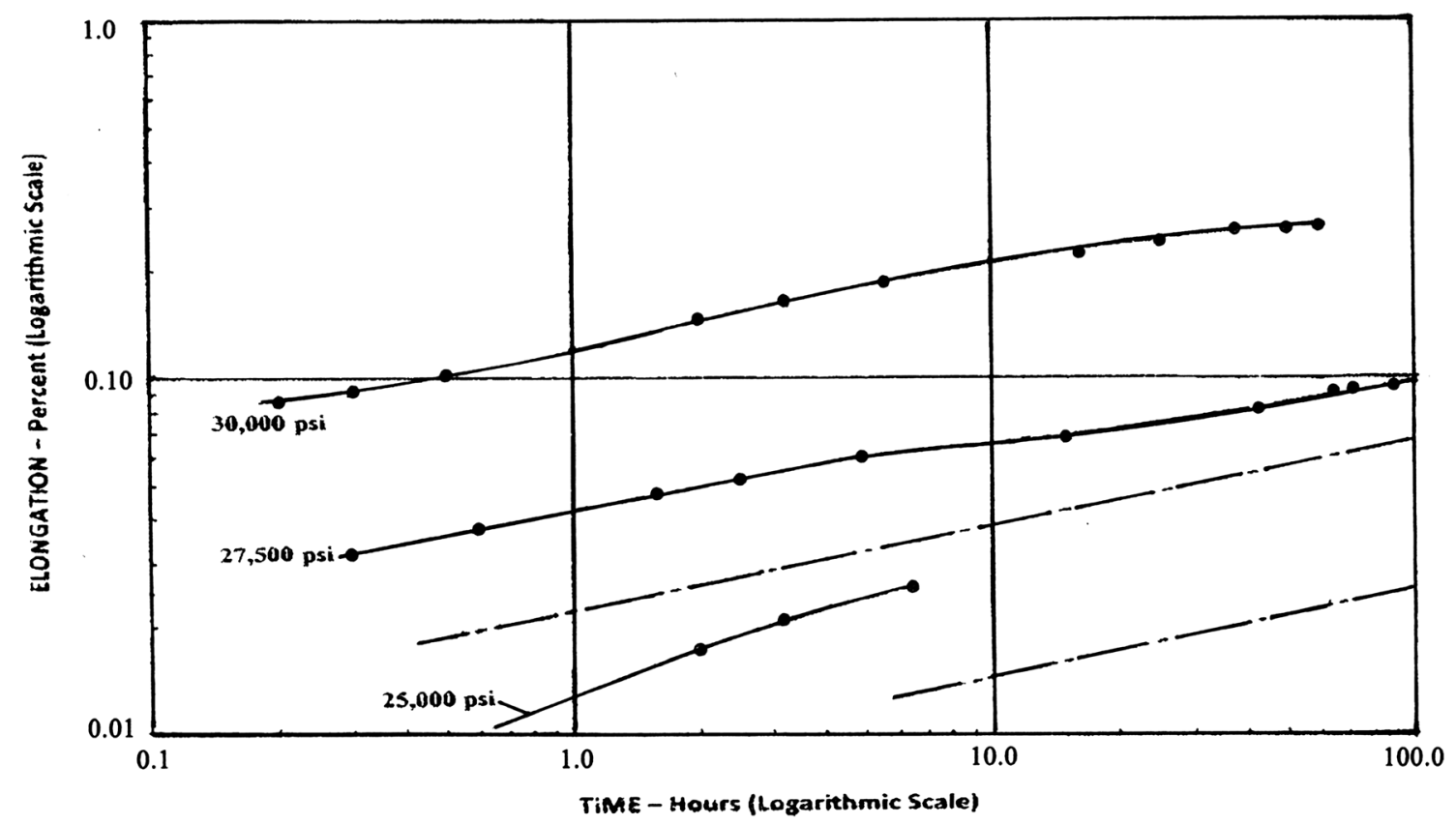

Fig. 5 Room temperature creep curves for an aluminum wheel alloy (solid lines) and pure aluminum (broken lines). Pure aluminum tested at 15,000 and 10,000 psi by Sturm et al. [4]

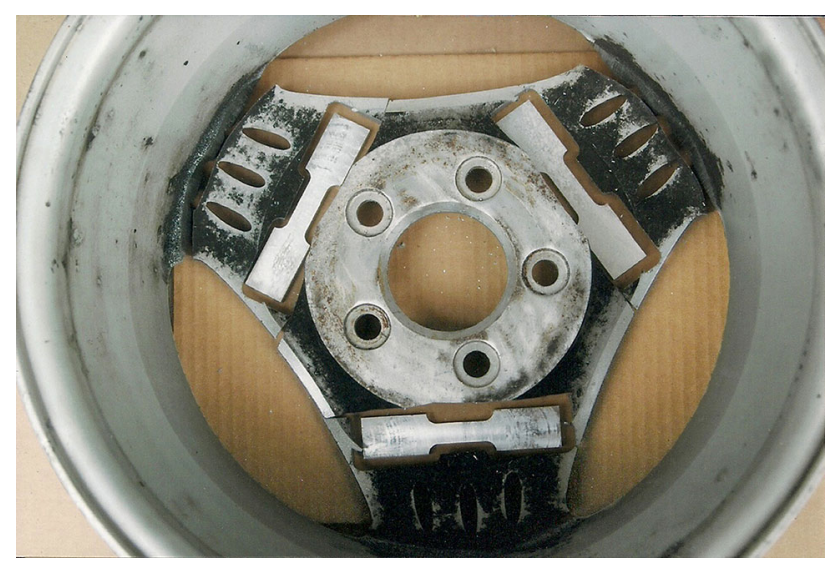

Fig. 6 Location of creep test specimens

that creep relaxation occurs in both steel and aluminum wheels and in the wheel attachment components at room temperature; the effect is accentuated at actual wheel operating temperatures, which can exceed 300F. Static, room temperature tests of wheel assemblies have been conducted using strain-gaged wheel bolts in OEM hubs, aluminum alloy wheels, and conical wheel nuts tightened to manufacturer's recommended torque values. These tests have shown an average loss of clamp force (bolt tension) of $10 \%$ after $24 \mathrm{~h}$ at room temperature. After $3 \frac{1}{2} \mathrm{~h}$ at $335 \mathrm{~F}$ (a measured wheel temperature during severe vehicle operation) the clamp force was reduced by $30 \%$. Again, these results do not include the exacerbating effects of increased forces acting on the bolts during vehicle operation. Static

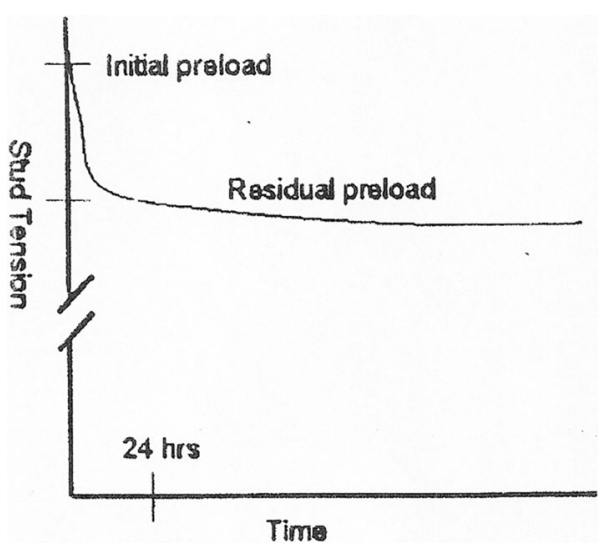

Fig. 7 Time-dependent loss of clamp force in a threaded joint. From Bickford [5]

and dynamic loss of clamp force is a reality and must be accounted for, either through a re-torquing requirement, which re-establishes the required clamp force on components which have adjusted their shapes to better accommodate each other through creep relaxation, or through selection of an installation torque sufficiently high to allow for the expected loss of clamp force and still provide a residual bolt tension sufficient to withstand the imposed road loads. A potential concern with the latter approach is that the higher the required installation torque, the less likely it is to be achieved during a roadside emergency wheel change (or even during a wheel removal/ re-installation operation in a service facility) and an increased likelihood of damaging the bolt (and/or brake 


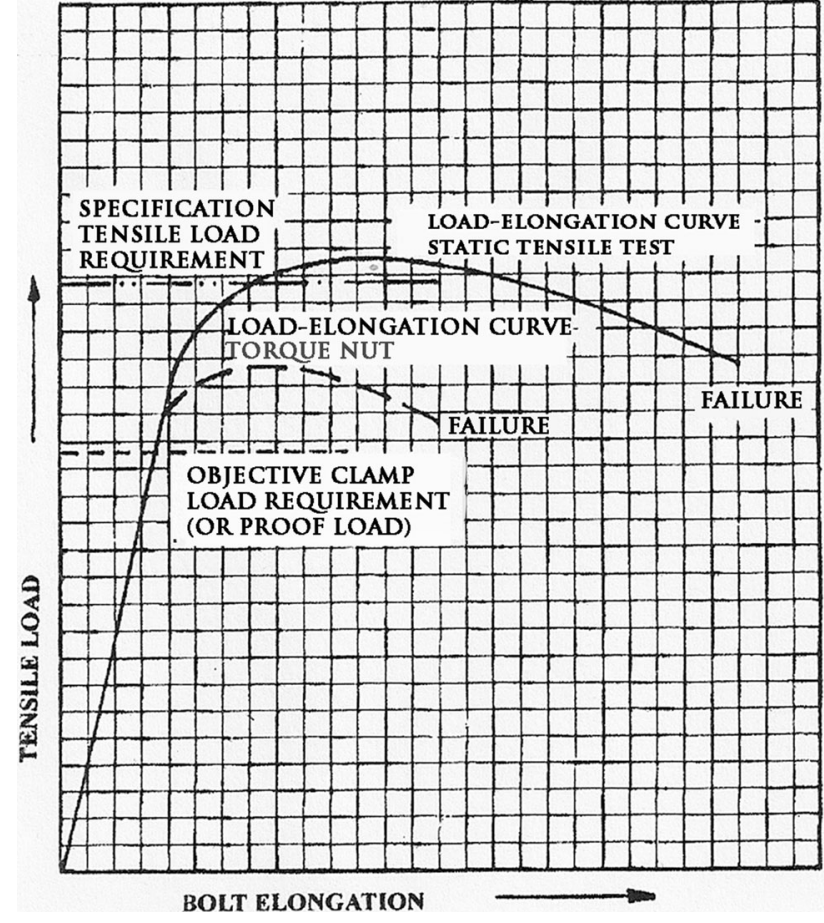

Fig. 8 Load-deflection curves for bolts tested in direct tension and in tension induced by tightening a nut. From Parmley [9]

drum or rotor) due to over-torquing. Also, it is a fact that bolts do not exhibit the same strength during the tightening of a nut as during a standard tensile test, and the selection of the wheel nut installation torque must be predicated on a lower value of bolt strength than is shown in standard bolt strength tables. For example, Fig. 8, reproduced from the work of Parmley [6], provides a comparison of the loaddeflection characteristics of a bolt when tested in direct tension versus torque-induced tension.

\section{Wheel Separation Mechanisms}

Wheel separations of the type being dealt with here are generally of two types: progressive unthreading and loss of the wheel nuts, and fatigue-induced fracture of the wheel bolts. Separations of the first type are more common on left-side wheels than on right-side wheels because the forward rotation of a wheel on the left side of a forwardmoving vehicle produces an unthreading motion on the right-hand threaded wheel nuts. The mechanism of this "unthreading" has been analyzed and described in detail by Herman [7]. Until about the mid-1980s, left-hand threaded fasteners were sometimes required on the left-side wheels of heavier model trucks and vans to counteract this effect. (See, for example the letter from J. N. Bradley of The Budd Co. to Mark Miller of GMC Truck \& Coach [8].) Unthreading separations have also been observed on right- hand threaded nuts on right-side wheels, however with significantly lower frequency. Fatigue-induced separations have been observed with roughly equal frequency on both sides of the vehicle.

The unthreading process must be preceded by a (nearly) complete loss of clamp force. This loss is typically the result of the torsional wheel loads (due to vehicle acceleration or braking torque) exceeding the available clampinduced friction force. Once relative motion between the wheel and its mating component is initiated, the unthreading process proceeds relatively quickly, particularly on left-side wheels.

The progress of a fatigue fracture is somewhat less straightforward than that of unthreading, but is also the result of the applied road-load forces exceeding the capability of the wheel bolt clamp force. The fatigue process in general occurs in distinct stages, beginning with crystallographic slip occurring on planes of high shear stress. With repeated removal and re-application of the slipproducing force, the slip gradually concentrates on selected planes, giving rise to a condition frequently referred to as "persistent slip." Continued cycling of the applied force produces "intrusions" and "extrusions" (the creation of microscopic interior and exterior surfaces along the persistent slip planes) which grow and become small cracks, again along planes of high shear stress. In the case of wheel bolts, these planes and the associated new surfaces are oriented at approximately a $45^{\circ}$ angle to the axis of the bolt. As the new surfaces grow, they can be recognized as incipient cracks. These cracks can be frequently observed as so-called "ratchet marks" on the final fracture surface. As the cyclic application of force continues and as the initial $45^{\circ}$ cracks reach a limiting size, further crack propagation proceeds along a plane of maximum normal rather than shear stress, and the continued progress of the fatigue crack takes place on a plane oriented at approximately $90^{\circ}$ to the axis of the bolt. Continued application of the cyclic force causes the crack to propagate in small steps until the remaining, unfractured volume of metal is not sufficient to withstand the applied force, and rapid final fracture occurs. The individual advances of the crack are too small to be viewed optically, but their progress is marked on the fracture surface by an array of generally concentric arcs, sometimes referred to as "beach marks." The fracture surface of a typical fatigue-induced fracture of a wheel bolt is shown in Fig. 9. The characteristic features of "ratchet marks," "beach marks," and the area of rapid final fracture are indicated.

The initial crack formation stage of fracture is usually very lengthy and occupies the majority of the fatigue life of a wheel bolt. The fatigue crack is not usually detectable through standard nondestructive test methods until it has progressed well beyond the stage of intrusions 
and extrusions. Therefore, a wheel bolt in service may have incurred fatigue "damage" which is not detectable but which has substantially impaired the serviceability of the bolt. For this reason, it is often recommended that in the event of a fatigue failure of a single wheel bolt, all wheel bolts in the assembly be replaced.

Fatigue-induced fractures are typically the result of repeated application of the radial forces associated with the rotation of the wheel while supporting a portion of the weight of the vehicle rather than with the torsional forces associated with vehicle accelerations and decelerations. Unlike the unthreading process, the fatigue-induced fracture of a wheel bolt does not require the complete loss of clamp force. Referring to the relationships shown by Parisen, the general shape of which has been shown to apply also to vertical loads, if the portion of the applied vertical load directed through the wheel nuts to the wheel bolts exceeds the "fatigue strength" of the bolt, the fatigue

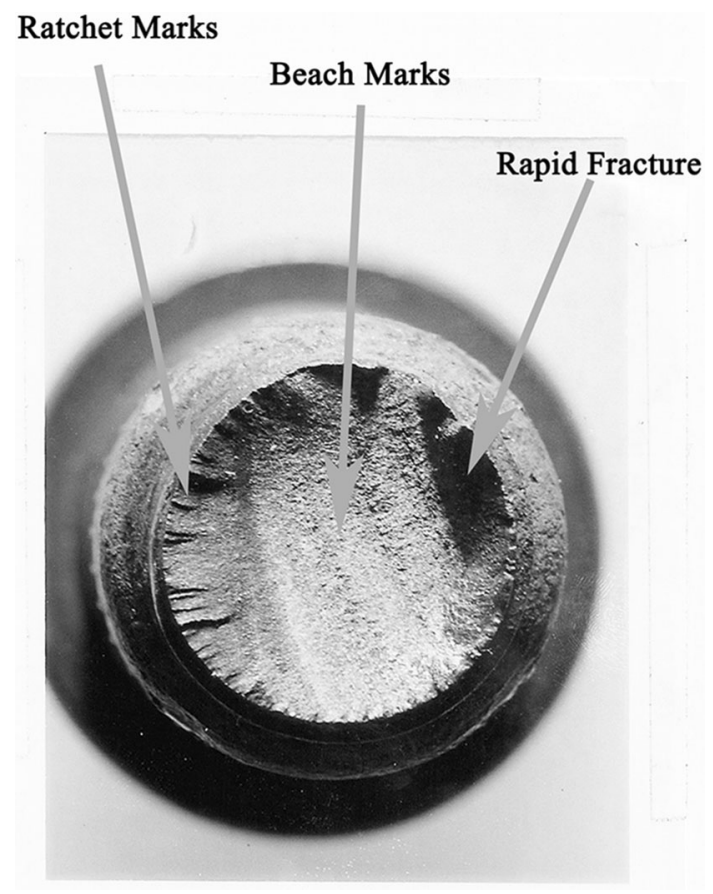

Fig. 9 Fatigue-induced fracture of a wheel bolt fracture process will be initiated. It must be borne in mind that for any given wheel the exact nature of the relationship shown in Fig. 3 depends on many factors, including the material and design of the wheel, the number, size, disposition of the wheel bolts, etc. Extensive laboratory testing of wheels and wheel bolts using a modified SAE Wheel Radial-Fatigue Test machine ("Bull Wheel" test) has shown that the general tendency is for a single wheel bolt to fracture in the absence of significant loss of clamp force in the other bolts and in the absence of apparent fatigue damage on any of the surviving wheel bolts, one example of such testing is shown in Table 1.

The surviving wheel bolts were examined microscopically and using NDT techniques without finding evidence of additional cracks. Other similar Bull Wheel tests have shown that after half or more of the bolts have fractured the residual torque on the remaining bolts is severely reduced, often to zero.

The tendency for a single bolt to fracture without significant loss of clamp force or detectable cracking of the surviving bolts has also been observed in the field, as, for example, in a recent incident involving a wheel separation from a SUV. The left rear wheel separated from the vehicle due to fatigue-induced fracture of the five wheel bolts, resulting in loss of vehicle control and a rollover accident. An investigator undertook to measure the residual torque on the five wheel nuts holding the right rear wheel in place. As he began to apply torque in the tightening direction to the first of the five wheel nuts, the bolt fractured. He discontinued his efforts and brought the fractured bolt to a metallurgical laboratory for examination. It was determined that a fatigue crack had progressed across approximately $95 \%$ of the bolt cross section and that the attempt to measure the residual torque produced the final rapid fracture. Subsequent measurements of the residual torque on the remaining four intact bolts produced the results shown in Table 2. Inspection of the four intact bolts by NDT technicians revealed no indications of cracks.

The manufacturer's required installation torque for that vehicle was $85 \mathrm{lb}-\mathrm{ft}$. The differences between the required installation torque and the measured residual torque were

Table 1 Residual nut torque on $5 / 8^{\prime \prime}$ flange nuts with grade 5 bolts after 925,500 "Bull Wheel" test rotations. Initial nut torque was $275 \mathrm{lb}-\mathrm{ft}$

\begin{tabular}{lllllll}
\hline Bolt \#1 & Bolt \#2 & Bolt \#3 & Bolt \#4 & Bolt \#5 & Bolt \#6 & Bolt \#7 \\
$270 \mathrm{lb}-\mathrm{ft}$ & 270 & 300 & Fracture & Fracture & 300 & 300 \\
\hline
\end{tabular}

Table 2 Residual nut torque on the right rear (intact) wheel of the accident vehicle

\begin{tabular}{lcccc}
\hline Bolt \#1 & $\# 2$ & $\# 3$ & $\# 4$ & \\
\hline Fractured & $64.2 \mathrm{lb}-\mathrm{ft}$ & 91.3 & 86.5 & \\
\hline
\end{tabular}


not inconsistent with values that should be expected for the particular wheel design after the mileage accumulated since installation due to static and dynamic effects.

\section{Bolt Piloting and Hub Piloting}

Virtually, all wheels are piloted (i.e., positioned on their mating surfaces) using either the wheel bolts or the center hub as the positioning feature. In bolt-piloted systems, the geometric features of the wheel nuts (usually either spherical or conical) mate with similar features formed at the bolt holes of the wheel so that when the nuts are tightened the nuts force the wheel to assume a position in which the mating surfaces are "nested" and the bolt circle of the wheel (the theoretical circle formed by the centers of the bolt holes) coincides with the bolt circle of the hub (the theoretical circle formed by the centers of the wheel bolts). In hub-piloted systems, the center hole of the wheel is piloted on the hub itself, requiring that both be machined to very exacting standards and that the diameter of the wheel center hole be only slightly greater than the diameter of the hub. The bolt hole areas of the wheel are then flat (lacking the conical or spherical surfaces present in bolt-piloted designs) and are larger than the major diameter of the wheel bolts so that the wheel slides easily over the bolts. In the recent history of light vehicles (since at least the 1930s), bolt-piloted designs have predominated. Hub-piloted systems began to emerge in the early 1980s to serve a specific purpose, that purpose being to enable the conversion of a greater portion of the applied nut installation torque into bolt tension, or wheel clamp force. In order to appreciate how this enabling occurs, it is necessary to examine the physical features of the wheel nuts employed in the two systems and how those features influence the conversion of applied torque into clamp force.

The nuts employed in the two systems are necessarily different: the bolt-piloted system utilizes a solid, one-piece

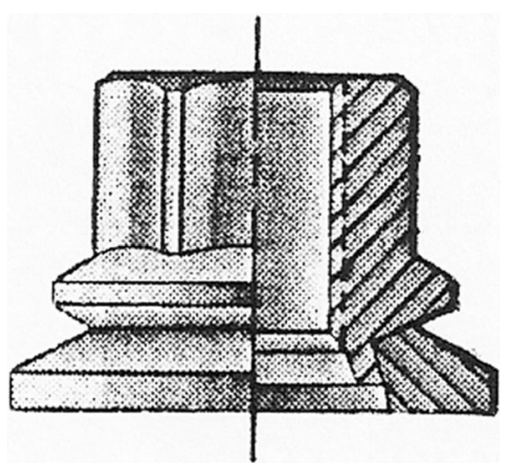

Fig. 10 Cutaway sketch of a two-piece nut used with hub-piloted wheels nut with either a conical or spherical contact surface to mate with and position the wheel, while the hub-piloted system requires a flat-faced nut so that the positioning of the wheel is accomplished by only the hub with no competing interference from the nut and bolt hole contact surfaces. The flat-faced nut is almost always of a particular two-piece design similar to that shown in the cutaway drawing of Fig. 10. The bottom, or "washer" portion of the nut, which is attached loosely (it is free to rotate independently) to the threaded portion through a swaging operation and contains a conical-shaped inner surface that mates with a similar conical shape in the threaded portion. This permits the washer portion to remain stationary and in contact with the wheel while the threaded portion rotates and advances along the threads of the wheel bolt during the nut installation process. The significant feature of the nut design is that the diameter of the conical contact surface between the two portions of the nut is significantly less than the diameter of the wheel contact surface of the washer portion. The importance of this difference can be appreciated from a consideration of the relationship between the installation torque and the bolt tension (or wheel clamp force). Several such mathematical relationships have been provided in the literature, the most common and straightforward of which is that provided below $[9,10]$.

Laboratory tests using strain-gaged bolts (torque-tension tests) have repeatedly shown a linear relationship between the applied torque and the product of the nominal diameter of the bolt and the resulting bolt tension. This empirical relationship permits the determination of the relationship between the applied torque, the geometric features of the nut and bolt, and the resulting bolt tension, as shown below:

$T=K \times D \times W$

where $T$ is the applied torque, $K$ is an empirical constant ("Torque Coefficient"), $D$ is the nominal diameter of the bolt, and $W$ is the resulting bolt tension (or clamp force).

From an analysis of the forces acting on the nut, bolt, and nut seat:

$$
\begin{aligned}
K= & U b \times R b / D \\
& +R t / D[(U t \sec B+\tan C) /(1-\sec B \times \tan C)]
\end{aligned}
$$

where $U b$ is the coefficient of friction acting at the nut-wheel interface, $U t$ is the coefficient of friction acting on the thread contact surfaces, $R b$ is the effective radius of action of the nut-to-wheel friction forces, $R t$ is the effective radius of action of the thread friction forces, $B$ is the thread half-angle (normally $30^{\circ}$ ), $C$ is the helix angle of the thread, and $D$ is the nominal bolt diameter. 
Fig. 11 Effects of repeated installation on the torquetension characteristics of wheel bolts

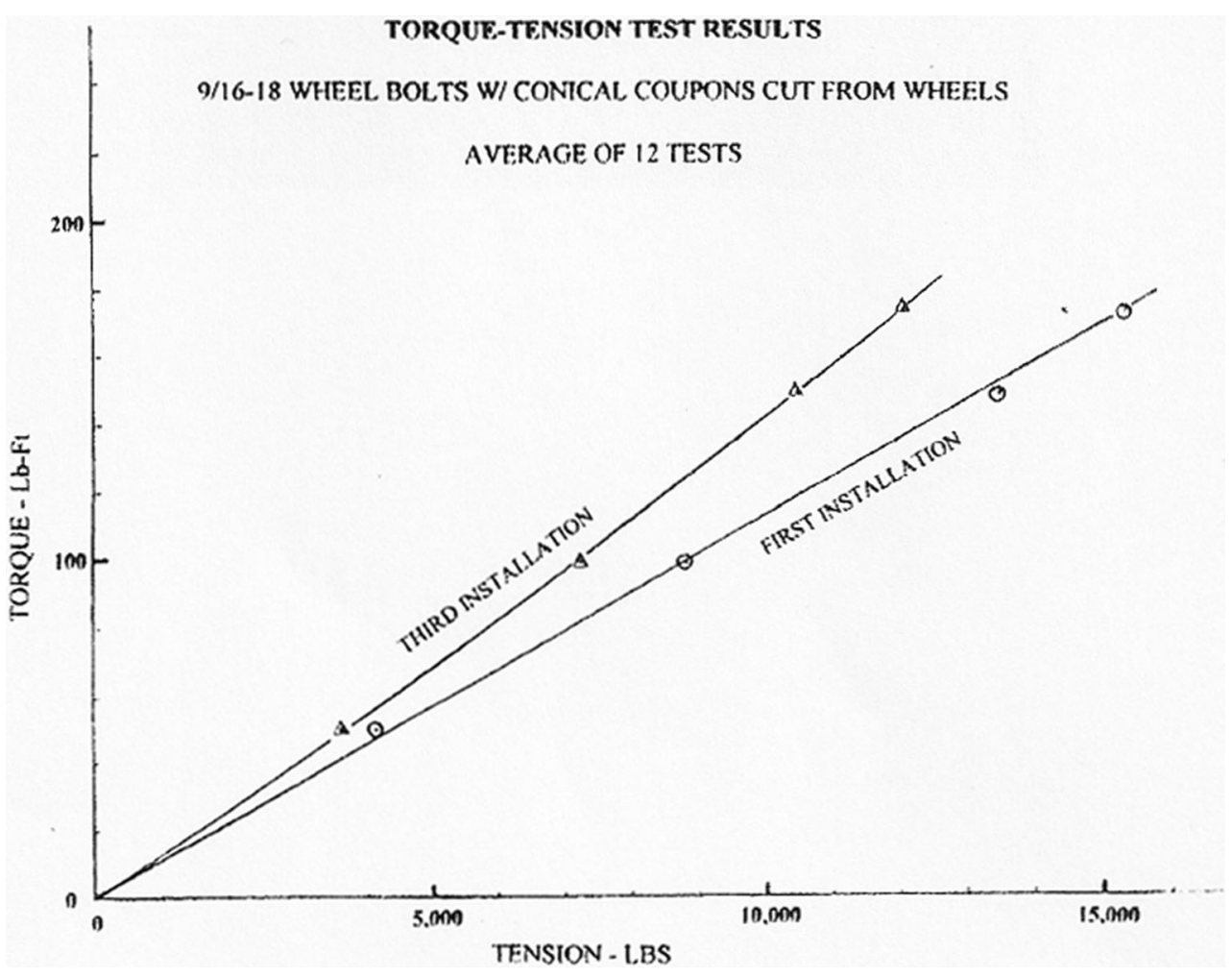

Normally, the denominator within the bracketed term is equal to unity within about $0.5 \%$, which permits Eq 2 to be simplified as:

$$
\begin{aligned}
K= & U b \times R b / D+U t \times(R t / D) \times \sec B+(R t / D) \\
& \times \tan C
\end{aligned}
$$

The first of the three terms on the right-hand side of Eq 3 describes the portion of the applied torque consumed in overcoming friction at the nut-to-wheel contact surface; the second describes the portion consumed in overcoming thread friction; and the third describes the portion converted into bolt tension, or wheel clamp force. When appropriate values for wheel bolts and one-piece nuts are inserted into Eq 3, it is found that approximately $50 \%$ of the applied torque is consumed in overcoming nut-to-wheel friction, approximately $40 \%$ in overcoming thread friction, and only about $10 \%$ is actually realized as bolt tension or clamp force. Obviously, any action taken to reduce the friction resistance of the nut-to-wheel contact surfaces will result in correspondingly increased bolt tension, or clamp force. The two-piece flat-face nut accomplishes this by significantly reducing the radius at which the friction acts $(\mathrm{Rb}$ in Eq 3). A typical two-piece nut will reduce this radius by approximately $45 \%$. This effect can be further enhanced by the application of a small amount (a few drops at most) of liquid lubricant on the conical surfaces of the nut, as is sometimes recommended in service manuals. (This lubrication also counteracts the negative effects of repeated loosening and re-tightening of the nuts.) Secondary benefits of the two-piece flat-face wheel nut lie in the fact that elimination of the conical nut seat surfaces in the wheel significantly reduces opportunities for mismatch in the assemblies, and the reduction in the areas of the conical contact surfaces slightly reduces the effective friction coefficient.

Each removal and re-installation of a wheel nut produces a small but significant deterioration in the torquetension characteristics of the nut and bolt due to increases in the frictional resistance. The curves shown in Fig. 11 show the effects of the increased friction on the tension generated in wheel bolts on the third installation. The tests were conducted using new bolts and conical nuts installed on coupons containing conical nut seats and cut from steel wheels. Other tests on $9 / 16$ bolts and conical nuts showed a reduction in clamp force in excess of $40 \%$ between the first and the sixteenth installation. The application of a very small amount of lubricant on the contact surfaces of twopiece nuts during field service is intended to counteract this type of deterioration as well as to combat the deleterious effects of environmental exposure.

Hub-piloted wheels are subject to unique field service problems due to the necessarily very close fit between the outer diameter of the hub and the inner diameter of the 
wheel center hole. For example, after long periods of exposure to the elements, particularly in northern climates where road salt is used, corrosion buildup between the hub and center hole surfaces can make the wheel extremely difficult to remove, especially during an emergency roadside wheel change. Then, in order to remove a wheel, it is frequently necessary for the driver to slightly loosen the wheel nuts, drive the vehicle forward for a few feet, and rapidly apply the brakes to induce sufficient braking torque on the wheel to break the corrosion bond and free the wheel. He can then raise the wheel end and remove the wheel in the normal manner.

Because of the increased cost of manufacture of the hubpiloted system components and the service problems peculiar to hub-piloted wheels, and because the benefits of hub piloting are particularly advantageous in the more rigid dual rear wheel assemblies where higher clamp forces are required, the use of hub-piloted wheels is virtually confined to higher GVWR dual rear wheel vehicles.

It has been reported in the literature [11] that a hubpiloted wheel attachment system actually provides additional support for the wheel in that a portion of the vertical road-load forces is transferred directly to the hub through contact between the wheel center hole and the hub. This is not correct! Just as in the bolt-piloted systems, all road loads are transferred from the hub-piloted wheel to the hub through the friction connection provided by the nut clamp force and the shear and bending forces applied through the nut to the wheel bolt.

As noted above, flat-faced nuts must be used with hubpiloted wheels to prevent an unwanted interference condition. If conical (or spherical) nuts and associated wheels are used in a hub-piloted system and if the centers of the bolt circles are not exactly coincident with the centerline of

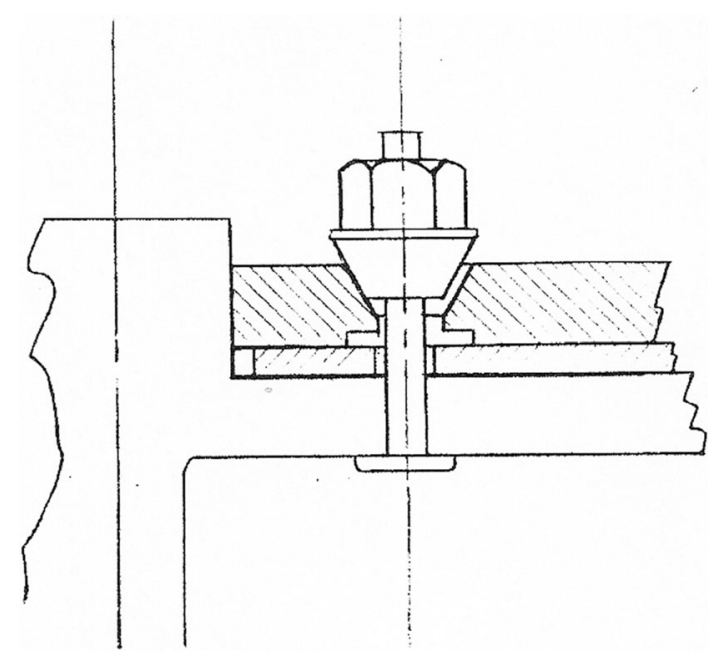

Fig. 12 Mismatch condition created by the use of cone nuts with a hub-piloted wheel the hub, the two piloting systems will interfere with each other, giving rise to very high local stresses in the areas of the nut seats. This interference condition is depicted schematically in Fig. 12. The very high local stresses created by this interference condition would greatly increase creep relaxation effects and the corresponding loss of clamp force.

Hub piloting of wheels was not intended as, nor has it succeeded in being, a superior method of "centering" the wheel and thereby improving ride quality through reduced vibration. Modern wheel manufacturing methods enable the production of bolt-piloted wheels with "centering" capability functionally equivalent to that of hub-piloted wheels. Automobile manufacturers have long recognized that ride quality (vibration) is controlled more by wheel bead seat contour and tire dimensions than by their capability to improve the "centering" of the wheel. Some auto manufacturers employ a "match mark" system of wheel and tire assembly in which the high (maximum diameter) spot on each tire is marked and matched with the similarly marked low (minimum diameter) spot on the wheel bead seat to produce a more nearly circular tire periphery. The secret to improved ride quality (reduced "vibration") lies in improved dimensional control of wheel bead seat contour and tire dimensions rather than in improving the "centering" of the wheel. Evaluations of the ride quality characteristics of bolt-piloted and hub-piloted wheels on the same vehicles by at least one vehicle manufacturer were unable to distinguish between the two attachment systems on the basis of ride quality ("vibration") characteristics.

Some investigators have proposed that "vibration" due to inaccurate "centering" of a wheel has been the cause of wheel bolt fatigue fracture and subsequent wheel separation.

No test data or engineering analyses have been advanced to support such a presumption. In fact, it is widely accepted that vibration alone is not capable of inducing the loosening of a properly tightened wheel nut [12]. In the late 1970s, a vehicle manufacturer conducted field and provingground evaluations of vehicles which had suffered premature deterioration of non-lubricated steering linkage ball studs leading to a very violent vehicle "shimmy" condition. In some cases, the shimmy vibrations were so violent that it was very difficult to maintain steering control of the vehicle. Although this condition affected a significant number of vehicles (primarily commercial vehicles in which the front axles were subject to unusually high loads) and was corrected through recall action, there were no reported incidents of associated wheel loosening or separation. Although there is no physical evidence to suggest that "vibration" is a precipitating cause of the loosening of properly tightened wheel nuts or the loss of wheel clamp 
Fig. 13 Relationship between clamp force and wheel bolt fatigue life

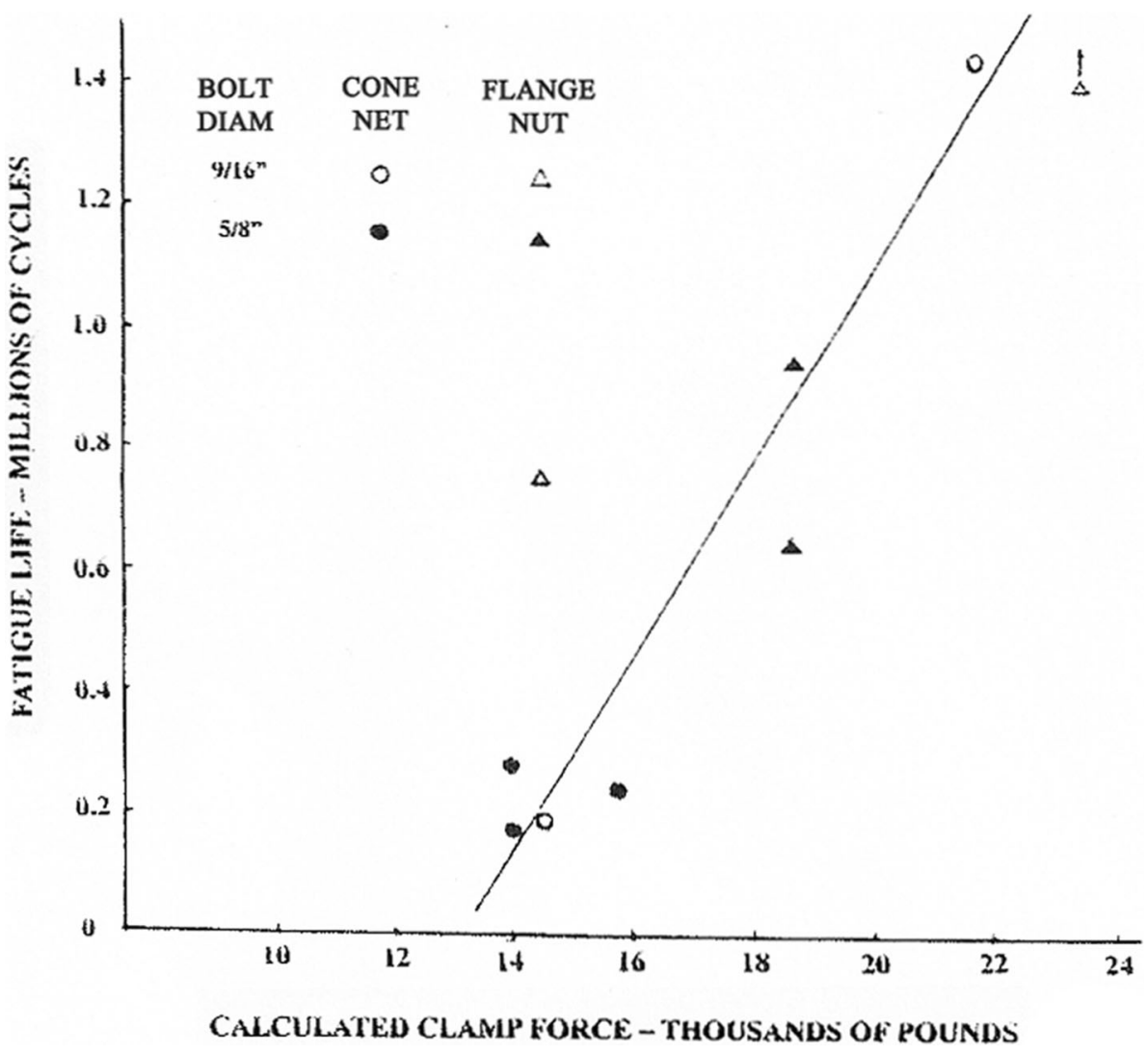

CALCULATED CLAMIP FORCE - THOUSANDS OF POUNDS force, it is possible that once the clamp force is lost due to other factors, vibration may accelerate the unthreading of a wheel nut.

The relationship between clamp force and fatigue life is illustrated in the Bull Wheel test data plotted in Fig. 13. These tests evaluated the fatigue lives of $5 / 8$ and 9/16 inch Grade 8 wheel bolts with solid conical and flange nuts, steel wheels, and wheel nut torques ranging from 175 to $275 \mathrm{lb}-\mathrm{ft}$. The initial clamp force was calculated using Eqs 1 and 3 provided above. Fatigue life was taken as the number of cycles accumulated before the first bolt failure.

The nature of the relationships provided by Parisen suggests that it might be possible to arrest the development of a fatigue crack through the timely application of additional nut torque to increase the clamp force. At least one instance of this type of intervention has been reported in the literature and is recounted below:

...an ultrasonic flaw detector was used to routinely monitor a group of 28 large cyclically loaded bolts. Over the first year of the project, we found several cracks and developed the ability to predict their growth. Then we found another bolt, one with a very small crack. It didn't have to be changed right away, and maintenance was backlogged. We continued to run the machine for several months while the crack slowly grew larger. Eventually we got a new hydraulic torque wrench and tightened the bolt to the required 17,500 ft.lb. After this re-tightening, the machine ran for an additional 30 million cycles, and several inspections found no additional crack growth before the bolt was changed [13].

Investigations of field separations have suggested, but have not confirmed, that similar incidents have occurred with wheel bolts. No actual data have been advanced to substantiate such a remedial procedure on wheel attachments, however.

Some investigators have expressed the belief that a wheel separation arising out of an installation error must occur within some relatively short period of usage, for example less than two thousand miles. Although this is often the case, it is not necessarily true. The process of static and dynamic clamp force deterioration continues indefinitely, albeit at a steadily reducing rate, and the vehicle operating conditions, particularly vehicle weight, maneuver forces, and road surfaces, are subject to unpredictable changes over time. For example, in the late 1970s a vehicle manufacturer undertook a vehicle durability test in which a pickup truck was scheduled to complete 23,000 miles of smooth- and rough-road testing while being carefully monitored and controlled by test engineers. The 
Table 3 Accuracy and relative cost of common methods of establishing a desired bolt preload

\begin{tabular}{lcc}
\hline Assembly method & Accuracy $(\%)$ & Relative cost \\
\hline Operator's feel & \pm 35 & 1 \\
Torque wrench & \pm 25 & $1-1.5$ \\
Turn-of-the-nut & \pm 15 & 3 \\
Load indicating washers & \pm 10 & 7 \\
Fastener elongation & $\pm 3-5$ & 15 \\
Strain gages & \pm 1 & 20 \\
\hline
\end{tabular}

test was interrupted after 11,329 miles by a right rear wheel separation due to fatigue-induced bolt fractures. The residual torque on the left rear (intact) wheel nuts showed a torques 15 to 25 percent below installation requirements. The cause of the separation was determined to be improper installation.

There are many techniques for establishing a desired bolt preload, each of which carries with it a burden of cost and an inherent level of reliability. The cost and reliability of several methods have been summarized and reported as in Table 3 [9, 14].

Part of the source of the inaccuracy associated with the use of a torque wrench arises from the difference between static and dynamic friction coefficients and from the need to periodically re-calibrate the wrenches (a need that is too frequently unfulfilled). Tests comparing torque values set dynamically on light truck wheel assemblies using automated tooling and then measured statically ("breakaway" torque measured in the tightening direction) have shown the static measurements to range from 25 to 35 percent higher. Regardless of the technical problems associated with the use of torque wrenches, they remain the most widely used method for setting and measuring wheel nut torques. Within the past few years, however, devices known as "torque sticks" have become increasingly popular as a means of setting wheel nut torques in vehicle service facilities. Torque sticks are intended for use with air impact wrenches and are designed such that the torsional flexibility of the shank of the socket wrench does not permit the installation torque to exceed the value for which the shank has been sized. Thus, a different socket is required for each desired level of installation torque. In the late 1990s, a major automotive manufacturer undertook to evaluate a particular brand of torque sticks for the purpose of approving them for use in their service facilities. Their testing showed that particular torque stick to be substantially superior to the torque wrenches then in use and to consistently demonstrate an accuracy better than $\pm 10 \%$ when evaluated on strain-gaged wheel bolts.

\section{Summary}

The frequency of vehicle accidents attributable to wheel attachment failures on light-duty (non-dual rear wheel) vehicles was extremely low prior to the advent of cast and forged aluminum alloy and forged "styled steel" wheels in the early 1970s. The sharp increase in such accidents which accompanied the rapid increase in the popularity of the more attractive solid wheels was attributable to a widespread failure among many after-market (and some OEM) suppliers and service organizations to recognize that the stiffer cast and forged wheels required more stringent installation and maintenance standards than did the more "forgiving" stamped steel predecessors. Coincident with, but not in response to, the increased frequency of wheel attachment failures on light-duty vehicles, hub-piloted wheels were introduced on heavier (dual rear wheel) vehicles as a means of reducing the long-standing higher frequency of attachment failures on vehicles equipped with the heavy-gage forged steel wheels. This reduction was accomplished by increasing the portion of the installation torque converted to wheel clamp force through a reduction in the portion lost to nut-to-wheel friction. Failure on the part of some investigators to recognize the factors responsible for the increased incidence of wheel separations on light-duty vehicles and the unique features of hubpiloted wheels gave rise to the formulation and propagation of myths and misconceptions regarding the causes and cures for such separations. It was the purpose of this paper to identify critical features of wheel and wheel attachment designs and of their installation and maintenance requirements that relate directly to attachment failures and to dispel some of those myths and misconceptions.

\section{References}

1. J. Parisen, Automobile Wheel Attachment Design Considerations. Paper 8220340 (SAE International, Warrendale, PA)

2. J. Searle, The Detachment of Wheels from Commercial Vehicles. Paper 861974 (SAE International, Warrendale, PA)

3. M. Bailey, J. Bertoch, Mechanisms of Wheel Separations. Paper 2009-01-0111 (SAE International, Warrendale, PA)

4. R. Sturm, C. Dumont, F. Howell, A Method of Analyzing Creep Data. J. Appl. Mech. 58, A62-A66 (1936)

5. J. Bickford, An Introduction to the Design and Behavior of Bolted Joints (Marcel Decker Inc, New York, 1998)

6. R. Parmley, Standard Handbook of Fastening and Joining (McGraw Hill, New York, 1996)

7. C.A. Herman, Technical report W-87-S (The Budd Co., 1956)

8. Letter from J. N. Bradley (The Budd Co.) to Mark Miller (GMC Truck \& Coach), Nov. 2, 1976

9. Tightening Torque for Screws, Bolts and Nuts. Industrial Fastener Institute-Technical Data, 1967

10. Fastener Engineering Handbook (Anchor Bolt and Screw Co., 1969) 
11. C. Roberts, Jr., Automotive Wheel Detachment. Fastener Technology International, August-September, 2013

12. G. Haviland, Unraveling the Myths of the Fastener World. Paper 810509 (SAE International, Warrendale, PA)
13. N. Sachs, Practical Plant Failure Analysis (CRC Press, Hoboken, 2007)

14. R. Irving, "Who Knows How Tight is Tight", Iron Age, October 1,1968 